\title{
Endogenous Pyrogen Production by Hodgkin's Disease and Human Histiocytic Lymphoma Cell Lines In Vitro
}

\author{
Phyllis Bodel, $\nmid$ Peter Ralph, Karen Wenc, and John C. Long, Department \\ of Medicine, Yale University School of Medicine, New Haven, \\ Connecticut 06510; Sloan-Kettering Institute for Cancer Research, Rye, \\ New York 10580; and The Immunopathology Unit, Department of Pathology, \\ Massachusetts General Hospital, Boston, Massachusetts 02114
}

\begin{abstract}
A B S T R A C T Fever not explained by infection may occur in patients with malignant lymphoma presumably caused by a release of endogenous pyrogen. Although pyrogen has been found in some tumors with a mixed cell population, production of endogenous pyrogen by the neoplastic cells has not been demonstrated. This report documents the apparently spontaneous synthesis and release of such pyrogen by two human tumor cell lines derived from patients with Hodgkin's disease and histiocytic lymphoma. The endogenous pyrogen from the two cell lines was similar and closely resembled that produced by normal human monocytes in antigenic properties as well as heat and pronase sensitivity. The Hodgkin's disease and histiocytic lymphoma cell lines do not require specific stimulation for the production of endogenous pyrogen suggesting that the mechanism of pyrogen release by neoplastic macrophage-related cells differs from that of normal phagocytic cells. The tumor-associated fever in some patients with malignant lymphoma may be caused by a release of endogenous pyrogen by proliferating neoplastic cells.
\end{abstract}

\section{INTRODUCTION}

Patients with malignant lymphoma, especially Hodgkin's disease and histiocytic lymphoma, commonly develop fever $(1,2)$. Because no infectious agent can be implicated in such fevers it is likely that in some patients the febrile response is caused by the underlying malignant lymphoma. Tumor-associated fever in man, like those studied in animal models, may result from the action of endogenous pyrogen (EP), ${ }^{1}$ a small protein that acts on the temperature regulating neurons in the hypothalamus (3-5). Although tissues from several

\footnotetext{
† Deceased, 2 July 1978.

Received for publication $13 \mathrm{July} 1979$ and in revised form 20 September 1979.

${ }^{1}$ Abbreviations used in this paper: EP, endogenous pyrogen; PF, pyrogen-free.
}

human tumors, including Hodgkin's disease, have been shown to contain or release EP when studied in vitro $(6-8)$, there is no information as to whether host leukocytes, tumor cells, or both are responsible for the pyrogen production. We report here the apparently spontaneous and continuous in vitro production of EP from established cell culture lines derived from histiocytic lymphoma and Hodgkin's disease tumors. U-937 cells were derived from the pleural fluid of a patient with histiocytic lymphoma and express reliable monocyte characteristics $(9,10)$. The Hodgkin's disease tissue culture (RY cell line) was prepared from tumors in the spleen and maintained as an established cell line related to, and possibly derived from, cells of the monocyte-macrophage system (11).

\section{METHODS}

Cell cultures. The U-937 line was derived from the pleural effusion of a patient with generalized diffuse histiocytic lymphoma as described $(9,10)$. Its characteristics include NaF-inhibitable $\alpha$-napthol-AS-D-esterase, surface receptors for immunoglobulin (Ig)G and complement, phagocytic capacity for Candida and formalin-fixed Staphylococcus aureus, lysozyme synthesis and secretion, and absence of detectable Epstein-Barr virus genome. Although initially the line required a feeder layer for growth, it now grows as nonadherent cells in flasks, with RPMI 1640 medium and $10 \%$ fetal bovine serum.

The Hodgkin's disease culture line was prepared from tumor nodules in a spleen removed at staging laparotomy $(12,13)$. Methods of preparation and maintenance of long-term Hodgkin's disease monolayers, and descriptions of the morphology, cytogenetic, cell surface, enzymatic, and ultrastructural features of the cultured cell have been reported $(11,12,14)$. The Hodgkin's disease monolayer used in this study (RY cell line) has been carried in continuous cultures for $>3 \mathrm{yr}$, contains aneuploid chromosomes, and produces malignant tumors when transplanted into nude mice (13). The cultured cells contain lysozyme and $\alpha$-naphthol acetate esterase, are devoid of surface receptors for complement or the Fc portion of immunoglobulin, and are phagocytic for carbonyl iron and india ink but not for antibody-coated erythrocytes $(11,12)$. The Hodgkin's disease monolayer was maintained in Dulbecco's 
modified minimal essential medium with $15 \%$ cobalt-irradiated fetal bovine serum (Microbiological Associates, Walkersville, Md.).

Pyrogen assay. U-937 cells in exponential growth were washed three times with pyrogen-free (PF) RPMI medium and suspended at $5 \times 10^{5} / \mathrm{ml}$ in PF growth media, consisting of RPMI medium with $10 \%$ PF fetal bovine serum (Flow Laboratories, Inc., Rockville, Md.). After incubation for 36-48 h, when the cell concentration reached $1-1.8 \times 10^{6} / \mathrm{ml}$, medium was removed using $\mathrm{PF}$ equipment, centrifuged at $1,000 \mathrm{~g}$ for $10 \mathrm{~min}$ and frozen at $-60^{\circ} \mathrm{C}$ until assay. Pyrogen assay was carried out in mice, as described $(15,16)$. The Hodgkin's disease monolayer was dispersed with trypsin, washed three times with PF growth medium, and $2 \times 10^{6}$ cells planted in $75 \mathrm{~cm}^{2}$ plastic flasks (Falcon Labware, Div. of Becton, Dickinson \& Co., Oxnard, Calif.) with $10 \mathrm{ml}$ PF RPMI medium with $10 \% \mathrm{PF}$ fetal bovine serum. After incubation for $40 \mathrm{~h}$ medium was removed, centrifuged at $1,000 \mathrm{~g}$ for $10 \mathrm{~min}$, frozen at $-60^{\circ} \mathrm{C}$, and assayed for endogenous pyrogen in mice.

Preparation of antisera against partially purified human $E P$. Details of this procedure have been reported $(17,18)$. Briefly, EP-containing supernates from human blood leukocytes were concentrated and mixed with rabbit serum that contained antibodies to leukocyte products not including EP. After removal of the precipitate, rabbits were repeatedly immunized at monthly intervals with the remaining supernate mixed with incomplete Freund's adjuvant. Less than $0.05 \mathrm{ml}$ of the final antisera neutralized one rabbit dose of human EP. Details for incubation of supernates with antisera before pyrogen assay are given elsewhere (18).

Heat and pronase incubation. Pyrogenic supernates were heated at $56^{\circ} \mathrm{C}$ for $1 \mathrm{~h}$ or incubated with $1 \mathrm{mg} / \mathrm{ml}$ pyrogen-free pronase before assay in mice, as described (15).

\section{RESULTS}

U-937 cells were incubated in pyrogen-free culture media for $36-48 \mathrm{~h}$ and the supernate from the flasks tested in mice for pyrogenic activity. The results of a representative experiment are shown in Fig. 1. The supernate produced a prompt febrile response in mice, unlike control medium that had not been incubated with cells. The shape of the fever curve resembles that produced by injection of other EP in mice $(9,12$, 15,18 ), including culture supernates containing pyrogens from mouse macrophage tumor cells (19). Pyrogen was found in each of eight experiments with U-937. It did not appear in supernates of flasks incubated at $4^{\circ} \mathrm{C}$, containing comparable numbers of cells, or in $37^{\circ} \mathrm{C}$ incubations of media alone.

Culture medium from the Hodgkin's disease monolayer incubated in pyrogen-free medium for the $40 \mathrm{~h}$ was found to contain levels of pyrogenic activity similar to that of U-937 cells. The average fevers in mice injected with medium from the Hodgkin's disease culture is shown in Fig. 2. Each of 16 mice received $0.3 \mathrm{ml}$ of culture medium, equivalent to an amount derived from $\sim 1.5 \times 10^{5}$ cells, and 13 animals were administered $0.3 \mathrm{ml}$ of medium that had not been incubated with cells used as a control. Endogenous pyrogen activity was found in each of four experiments with Hodgkin's disease cultured cells and was not detected in medium

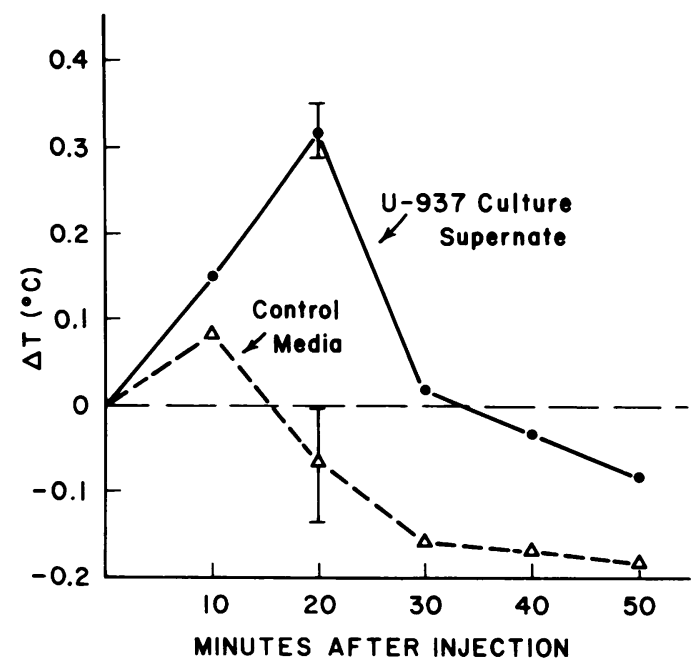

FIGURE 1 Spontaneous pyrogen release by histiocytic tumor cell line (U-937) during in vitro incubation. Average temperature change in groups of 9-19 mice after injections of culture supernates from 36-h incubations of cells or control media is shown. Each supernatant sample was derived from $1.5-3 \times 10^{5}$ tumor cells. SEM at $20 \mathrm{~min}$ are shown by brackets.

of flasks incubated at $4^{\circ} \mathrm{C}$ with comparable number of cells.

These results indicate that viable cells from the U-937 culture line and Hodgkin's disease monolayer spontaneously release pyrogen in the medium during in vitro propagation. We also tested extracts of cultured cells disrupted by freeze-thawing and could detect no intra-

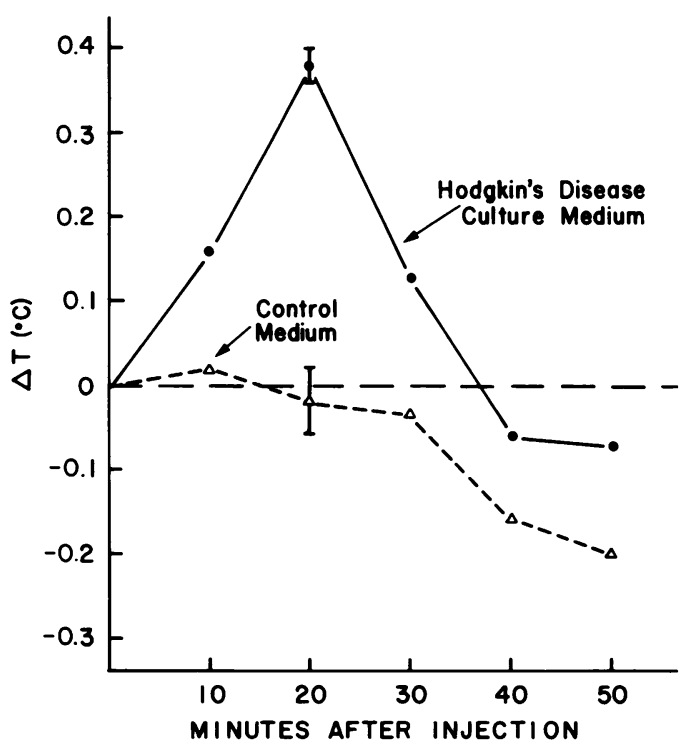

Figure 2 Average fevers in mice injected with culture medium from a Hodgkin's disease monolayer culture. Temperature response $(\Delta T)$ from base line in groups of 13-16 mice injected with $0.3 \mathrm{ml}$ of culture medium from a 40 -h incubation of cells or control medium is shown. SEM at $20 \mathrm{~min}$ are shown in brackets. 
cellular pyrogen. However, it is possible that pyrogen is present within the cell, but is destroyed by intracellular components, such as proteolytic enzymes, that are also released during the freeze-thawing process. When pyrogenic supernates were combined with extracts from freeze-thawed cells, no alteration of pyrogenicity was noted upon testing of the material. Thus, pyrogen appears to be produced and released during growth, not stored in detectable form.

To further characterize the pyrogen present in medium from these cultures, we incubated the supernates with normal rabbit serum and rabbit serum containing antibody against partially purified human leukocyte pyrogen. As shown in Table I, this antibodycontaining serum inactivates pyrogens produced by human blood leukocytes, but has no effect on pyrogens produced by rabbit blood leukocytes, mouse peritoneal macrophages, or a tissue culture line of mouse macrophage tumor cells. As shown in Figs. 3 and 4, incubation of media from the U-937 and the Hodgkin's disease cultures with the antibody-containing serum, but not normal rabbit serum, markedly reduced pyrogenicity of the supernatant medium. These results indicate that the pyrogens released by these cultured cells have a close antigenic relationship to pyrogens produced by other human leukocytes.

We also treated pyrogenic supernates from U-937 and Hodgkin's disease cultured cells with pronase to establish their similarity to other EP that have essential protein moieties $(5,8,15,19)$. As shown in Figs. 3 and 4 , pronase treatment inactivated the pyrogenicity of the culture supernates. These results indicate that pyrogen produced by both cell lines contains a protein essential for pyrogen activity. Moreover, it clearly differentiates the pyrogen from endotoxin, which does not lose pyrogenicity after incubation with pronase (20).

\section{DISCUSSION}

Tumor-associated fever has been recognized for many years, but its pathogenesis has remained obscure. Pyro-

TABLE I

Antibody Specificity of Anti-EP Serum*

\begin{tabular}{lcc}
\hline & & Pyrogenicity \\
\cline { 2 - 3 } \multicolumn{1}{c}{ Source of endogenous pyrogen } & NRS & Anti-EP serum \\
\hline Human blood leukocytes & + & - \\
Rabbit blood leukocytes & + & + \\
Mouse peritoneal macrophages & + & + \\
Mouse macrophage tumor cells $\S$ & + & +
\end{tabular}

* Rabbit serum containing antibody against human leukocyte pyrogen (18).

$\ddagger(+)$ a positive response after injection of supernatant samples incubated with sera.

\$ Cell line PU5-1.8 (19).

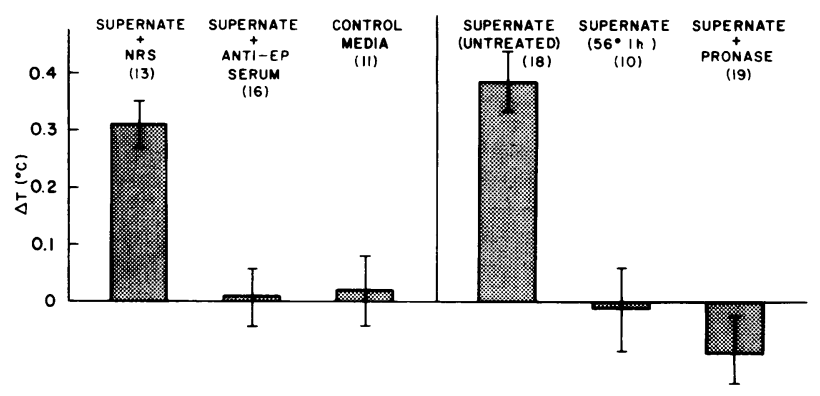

FIGURE 3 Inactivation of U-937 pyrogen by antiserum to partially-purified human leukocyte pyrogen (anti-EP serum), but not by normal rabbit serum (NRS), and by heat and pronase treatment. Average maximum temperature elevation \pm SEM, $20 \mathrm{~min}$ after injection of the supernates or control media into groups of mice, is shown by the height of the bars, and numbers of mice in parentheses. Details of pretreatments of pyrogenic supernatants are given in text.

gen release has been documented from lymphoid tissue incubated in vitro from patients with Hodgkin's disease $(6,7)$ and the presence $(21)$ and release $(8)$ of pyrogen from renal cell carcinoma tissue has been reported. In all such cases, however, both host leukocytes and tumor cells have been present in the tissues, and no distinction could be made as to which cell type or types were responsible for the EP production.

Recently, several mouse macrophage tumor cell lines were reported to release pyrogen during in vitro culture in pyrogen-free fetal bovine serum, whereas no pyrogen was detected in supernates from human fibroblasts, HeLa cells (16), hepatoma or renal cell carcinoma cell lines (19). Because it appears that of nonmalignant cells, only bone marrow-derived phagocytic cells have the capacity for normal pyrogen production and release after stimulation (16), we decided to study two macrophage-related tumor cell lines of human origin. Our

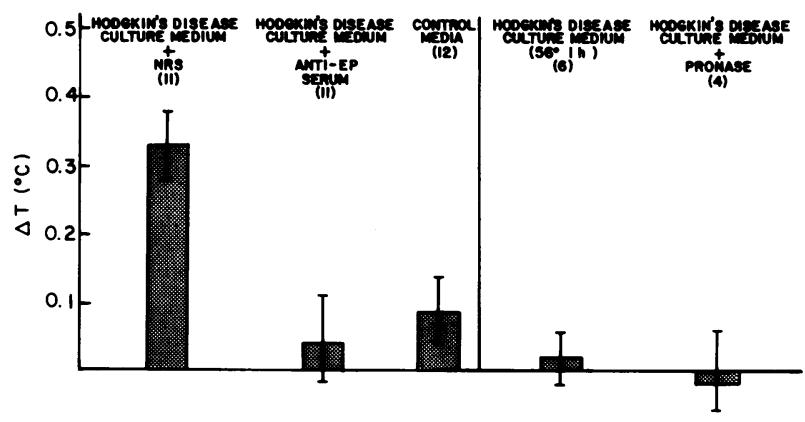

FIGURE 4 Average peak temperature elevations of mice injected with Hodgkin's disease culture medium treated with antiserum to human leukocyte pyrogen (anti-EP serum), normal rabbit serum (NRS), heat $\left(56^{\circ} \mathrm{C}\right.$ ), and pronase. $2.7 \mathrm{ml}$ of culture medium was incubated with $0.3 \mathrm{ml}$ of anti-EP serum or NRS at $37^{\circ} \mathrm{C}$ for $30 \mathrm{~min}$ and at $4^{\circ} \mathrm{C}$ overnight. After centrifugation the supernates were tested for pyrogen activity in mice. SEM are shown in brackets and numbers of mice injected in parentheses. 
results reported here indicate that these two culture lines, derived from histiocytic lymphoma and Hodgkin's disease, also have the capacity to produce and release pyrogen during in vitro culture in the absence of a known stimulus.

Monolayer cell cultures prepared from Hodgkin's disease tumors are composed of neoplastic cells. They are capable of continuous growth in vitro for an indefinite period of time, have aneuploid chromosomes, and produce malignant tumors when inoculated into nude mice. Morphologic, ultrastructural, and enzymatic studies suggest that cells of Hodgkin's disease monolayers are similar to macrophages $(11,12,14)$. However, the Hodgkin's disease cultures cannot be regarded as unequivocally of macrophage origin as has been convincingly shown for the U-937 histiocytic lymphoma cell line $(9,10)$. The Hodgkin's disease cell lines are devoid of several definite macrophage characteristics (surface receptors for complement and IgG and phagocytosis of antibody-coated erythrocytes). However, the endogenous pyrogen produced by Hodgkin's disease culture cells is similar to that of U-937 cells, a bona-fide human macrophage tumor cell line. Because lymphocytes and fibroblasts do not produce endogenous pyrogen, results from our study indicate that Hodgkin's disease cultured cells retain a macrophage functional capacity other than those thus far studied, the release of endogenous pyrogen.

The pyrogen of histiocytic lymphoma and Hodgkin's disease cell cultures appears to have characteristics similar in most respects to those of EP produced by normal human blood leukocytes after stimulation. It is heat-labile, contains an essential protein component, and apparently carries similar antigenic sites, since it is inactivated by sera containing anti-human EP antibodies. Like mouse macrophage tumor pyrogens, however, U-937 pyrogen consists of several different molecular weight species. One of these, of $\sim 14,000$ mol wt, may be the same molecule that is present in EP by human granulocytes and monocytes (22). Two larger pyrogenic species are also present, however; one is about $28,000 \mathrm{~mol} \mathrm{wt}$, and the other $60,000 \mathrm{~mol} \mathrm{wt}$, essentially at the exclusion volume of the G-75 column (unpublished data). Previous studies describe the existence and pyrogenicity of a larger molecular weight human leukocyte pyrogen (22). However, subsequent work shows trimerization of the 15,000-dalton larger molecular weight human leukocyte pyrogen into a 45,000-dalton molecule $(23,24)$.

We have shown that incubation with $S$. albus as a phagocytic stimulus induces the production of pyrogen by normal human, rabbit and mouse mononuclear phagocytes $(3,15,16,20)$, and augments production by mouse macrophage tumor cell lines (19). Similar incubations with U-937 showed no effect on pyrogen levels (not shown), consistent with their very low capacity for phagocytosis (9). The continuous production and secretion of this material by human and murine tumor lines in the apparent absence of a stimulus and the elaboration of unusually large pyrogenic molecules suggest that these cells possess altered mechanisms for EP production and release compared to those that exist in normal macrophages.

The demonstration that cell lines of Hodgkin's disease and human histiocytic lymphoma continuously release pyrogen during in vitro growth suggests that tumor-associated fever in some patients with lymphomas may be caused by pyrogen production and release by the proliferating neoplastic cells. Because not all patients with these diseases have fever, nor is fever present at all times, many factors relating to site and rate of EP production and destruction probably determine the final in vivo response.

\section{ACKNOWLEDGMENTS}

This investigation was supported by grants CA-24300, CA14655, and CA-19514 from the National Cancer Institute, Department of Health, Education, and Welfare and PCM 75-19734 from the National Science Foundation.

\section{REFERENCES}

1. Boggs, D. R., and E. Frei, III. 1960. Clinical studies of fever and infection in cancer. Cancer (Phila.). 13: 12301253.

2. Jones, S. E., Z. Fuks, M. Bull, M. E. Kadin, R. F. Dorfman, H. S. Kaplan, S. A. Rosenberg, and H. Kim. 1973. NonHodgkin's lymphomas. IV. Clinicopathologic correlation in 405 cases. Cancer (Phila.). 31: 806-823.

3. Atkins, E., and P. Bodel. 1974. Fever. In The Inflammatory Process. B. W. Zweifach, L. Grant, and R. T. McCluskey, editors. Academic Press, Inc., New York. 3: 467-514.

4. Atkins, E., and P. Bodel. 1979. Clinical fever: Its history manifestations, and pathogenesis. Fed. Proc. 38: 57-63.

5. Dinarello, C. A. 1979. Production of endogenous pyrogen. Fed. Proc. 38: 52-56.

6. Bodel, P. 1972. Pyrogen production in vitro by lymphoid tissue in malignant lymphoma. J. Clin. Invest. 51: 11 a. (Abstr.)

7. Bodel, P. 1974. Pyrogen release in vitro by lymphoid tissues from patients with Hodgkin's disease. Yale J. Biol. Med. 47: 101-112.

8. Bodel, P. 1974. Tumors and fever. Ann. N. Y. Acad. Sci. 230: 6-13.

9. Sundström, C., and K. Nilsson. 1976. Establishment and characterization of a human histiocytic lymphoma line. Int. J. Cancer. 7: 565-577.

10. Ralph, P., M. A. S. Moore, and K. Nilsson. 1976. Lysozyme synthesis by established human and murine histiocytic and lymphoma lines. J. Exp. Med. 143: 1528-1533.

11. Long, J. C. 1979. Immunopathology of Hodgkin's disease. Clin. Haematol. 8: 531-566.

12. Long, J. C., P. C. Zamecnik, A. C. Aisenberg, and L. Atkins. 1977. Tissue culture studies in Hodgkin's disease: morphologic, cytogenetic, cell surface, and enzymatic properties of cultures derived from splenic tumors. $J$. Exp. Med. 145: 1484-1500.

13. Zamecnik, P. C., and J. C. Long. 1977. Growth of cultured 
cells from patients with Hodgkin's disease and transplantation into nude mice. Proc. Natl. Acad. Sci. U. S. A. 74: 754-758.

14. Gang, D. L., J. C. Long, S-Y. Chi, and A. M. Dvorak. 1979. Electron microscopy of Hodgkin's disease tissue cultures. Cancer (Phila.). 44: 543-557.

15. Bodel, P., and H. Miller. 1976. Pyrogen from mouse macrophages causes fever in mice. Proc. Soc. Exp. Biol. Med. 151: 93-96.

16. Bodel, P., and H. Miller. 1977. Differences in pyrogen production by mononuclear phagocytes and by fibroblasts or HeLa cells. J. Exp. Med. 145: 607-612.

17. Dinarello, C. A., L. Renfer, and S. M. Wolff. 1977. The production of antibody against human leukocytic pyrogen. J. Clin. Invest. 60: 465-472.

18. Bodel, P., and H. Miller. 1978. A new sensitive method for detecting human endogenous (leukocyte) pyrogen. Inflammation. 3: 103-110.
19. Bodel, P. 1978. Spontaneous pyrogen production from mouse histiocytic and myelomonocytic tumor cell lines in vitro. J. Exp. Med. 147: 1503-1516.

20. Haeseler, F., P. Bodel, and E. Atkins. 1977. Characteristics of pyrogen production by isolated rabbit Kupffer cells in vitro. J. Reticuloendothel. Soc. 22: 569-581.

21. Rawlins, M. D., R. H. Luff, and R. I. Cranston. 1970. Pyrexia in renal carcinoma. Lancet. I: 1371-1373.

22. Dinarello, C. A., N. P. Goldin, and S. M. Wolff. 1974. Demonstration and characterization of two distinct human leukocytic pyrogens. J. Exp. Med. 139: 1369-1381.

23. Dinarello, C. A., L. Renfer, and S. Wolff. 1977. Human leukocyte pyrogen: purifications and development of a radioimmunoassay. Proc. Natl. Acad. Sci. U. S. A. 74: 4624-4627.

24. Dinarello, C. A., and S. M. Wolff. 1978. Pathogenesis of fever in man. N. Engl. J. Med. 298: 607-612. 